Besides all this there is the very generous promise of support from the King's Fund, in the event of amalgamation, by (1) contributing for five years the annual sum of $£ 1500$; and (2) guaranteeing the rent of the premises of the NorthWest London Hospital in the Kentish Town-road for ten years, and paying the cost of adapting these premises as an out-patients' department to the amount of $\$ 2000$.

The question as to whether or not the Hampstead practitioners would suffer by the transaction is not one which should influence the public in their decision. The point at issue is, Will these charitable institutions, to which the public have so generously subscribed, be thereby benefited? To the unprejudiced mind there can be but one answer: both institutions will undoubtedly in the truest sense be strengthened and their sphere of usefulness extended. It should be remembered that in carrying out a scheme such as this there must of necessity be changes involving cases of individual hardship; this is especially the case here at the North-West London Hospital. But it is gratifying to know that every one whose personal interest is at stake, be be doctor or layman, is prepared to stand on one side rather than put the smallest hindrance in the way of an undertaking which we all believe to be on the whole a wise and beneficent one. I am, Sirs, yours faithfully, ALFRED CRASKE, Secretary.

North-West London Hospital, Kentish Town-road, N.W., July 8th, 1907.

\section{PHYSICAL EXAMINATION OF SCHOOL CHILDREN.}

To the Editors of THE LANCET.

SIRs,-In your report of the proceedings of the Standing Committee on Mr. J. Wilson's Public Health Bill in THE LANCET of July 6th, p. 67, I am reported, probably owing to necessary condensation, as opposing the examination of children in elementary schools for infectious disease by the medical officer of health.

Clause 82 was so drawn that power would be given to the medical officer of health to make an extended physical examination of every child as well as to examine it for infectious disease. This was objected to, and Sir William Collins put down an amendment requiring that before any physical examination was made the written consent of the parent or guardian should be obtained. In supporting this amendment I pointed out that such written consent had usually to be obtained in secondary schools and I was opposed to the children of the poor being made to submit to a physical examination while the child of the richer parent would escape.

July 6 th, 1907. I am, Sirs, yours faithfully,

\section{AN ASPECT OF VACCINES AND ANTITOXINS. \\ To the Editors of THE LANCET.}

SIRs,-The halo of individuality which modern science sheds round the agents submitted for special uses tends to limit observation within the lines suggested. It is open to doubt whether this is entirely good. Specially is it questionable in such remedies as are derived from the blood of man or animals. The vaccines, serums, and antitoxins may contain recognisable individual products which have specific uses, but their life-history and the mode of their production class them with possible family associations which may be serviceable under other and not always allied conditions. It is now everywhere admitted that the lymph which Jenner used in his vaccinations was not even bacteriologically pure the admission is ample reason for all the research which has placed his operation on the sound basis which is the foothold of its present advocates. One, perhaps two, observations must have fallen to the lot of most medical men; the first, that vaccination performed in the early stages of some previously existent disease was frequently delayed, or prevented, in its evolution; secondly, that infantile eczema or impetigo was not a bar to successful vaccination, but rather that the successful vaccination was sometimes followed by a disappearance of the eczema. My own experience would tend to show that this result followed more frequently after the ase of humanised lymph than with the more pure and individualised calf products. The eldership of vaccinia should have placed it in the forefront of individuality as regards its scientific purity. My object in this note is to call attention to some possible bye-products, or nuclein derivatives, which may exist in the next elder of the serums. Some years since I was called upon to give a protective dose of the antidiphtheritic serum to several members of a family, one of whom was the subject of persistently recurring boils. To my great satisfaction the boils ceased immediately after the injection. The observation was too trite to be neglected. I offered to repeat the experiment in other cases of the same nature, as well as in cases of carbuncle. The results have convinced me that it is of great value and is usually successful. In some of my cases there was evidence of sugar in the urine, but $I$ have not had the opportunity to use the serum in the carbuncles of confirmed diabetes. I tried it without success in the pustular rash which sometimes attends the continuous administration of bromides. We see so little septic disease in Guernsey that one's stock of antistreptococcic serum is apt to grow stale. Once I required some under these conditions and was shut off by a Sunday's pest from obtaining more till the Tuesdav. As a "do.no better" I used the antidiphtheritic serum and with such good result that no other was required.

My first, and accidental, result was obtained from the use of 500 units, but in the selected cases I have used 2000 units. have no hesitation in asking for an extended trial of it in cases of boils and carbuncles; all my patients have been most grateful. Once again, the use of antistreptococeic serum is somewhat disturbing in early childhood. An infant was born of a mother who died 14 days later from puerperal septicæmia in India. The child had an abscess opened near the anus before it fell under my care, and it had a purulent discharge from the ear as well as a maintained temperature which if it seldom reached above $100^{\circ} \mathrm{F}$. also failed to touch the normal lower temperature of the day. After consultation with the uncle (who is an M.D., T.C.D.) I injected 500 units of the antidiphtheritic serum and the result was satisfactory. The ear discharge ceased, the temperature became normal, and the division of a small sinus near the anus restored the infant to perfect health. There is no finality in these results; they only raise the question of a limited individuality of the serums and perhaps suggest the lines of search for their family relationships.

I am, Sirs, yours faithfully,

Guernsey, June 21st, 1907.

J. AIKM $\Delta N$, M.D. Glasg

\section{MSS. OF JOHN HUNTER'S LECTURES.}

\section{To the Editors of THE LANCET.}

SIRs,-I possess a volume described on the back as "Hunters Surgery MS." which appears to be different from any which you have mentioned. It is written throughout in the first person (and beautifully written), contains 67 lectures, 422 quarto pages, with five more pages of index. The only indication of its date might be found in the following passage in the beginning of the first lecture: "This course will consist of about eighty lectures in weh (sio) I shall differ very much from what is taught in books upon this subject. I do not undertake to advance anything but what is built upon my own observations made in an attentive practice of 40 years and upwards." The index is a most careful précis of each lecture-for example, lect. 13-

Acquir'd Hereditary causes (of disease), Effects of $y^{e}$ mind on disease, Involuntary actn of voluntary parts, Symptoms, Anomalous symptoms, the difference in $y^{e}$ power of resist'g disease in $y^{e}$ different Structure of parts.

I would not like to part with the volume, which I regard as a precious heirloom, but if it is original the R.C.S. must have it. I am, Sirs, yours faithfully,

Southport, July 6th, 1907. Colin CaMpbell.

\section{THE APOTHECARIES ACT, 1907. To the Editors of THE LANCET.}

SIRs, - In view of the numerous inquiries I am receiving from those holding the diploma of the Society of Apothecaries as to the effect of the Act upon their diploma, may 1 be allowed to state that the result of the Act, so far as concerns those who have obtained the "L.S.A." since Jane 30th, 1887, is to enable them on application to the Society and on payment of the prescribed fee to have granted to them a diploma conferring the qualification of "Licentiate in Medicine and Surgery of the Society of Apothecaries." Subject 